\title{
Extradimension of fasciocutaneous flap in the surgical management of postaural fistula, a complication of chronic otitis media - squamous type
}

\author{
Madhubari Vathulya*, Manu Malhotra, Saurabh Varshney
}

Department of ENT, AIIMS Rishikesh, Rishikesh, India

Received: 08 December 2016

Accepted: 23 December 2016

\section{*Correspondence:}

Dr. Madhubari Vathulya,

E-mail: madhubari@yahoo.co.in

Copyright: () the author(s), publisher and licensee Medip Academy. This is an open-access article distributed under the terms of the Creative Commons Attribution Non-Commercial License, which permits unrestricted non-commercial use, distribution, and reproduction in any medium, provided the original work is properly cited.

\begin{abstract}
Post aural fistula is one of the complications of squamous variety of chronic otitis media (COM-S). For decades together a lot of new surgical techniques have been introduced in the treatment of COM-S out of which canal wall down mastoidectomy is most commonly practised. Despite these efforts many patients presenting with COM-S end up in tertiary referral centers at a late stage with complications like fistulas and by this time a number of procedures have already been done on them. A 19 year old female presents with Postaural fistula as a complication of COM- S type. Due to the local scarring, newer flap options needed to be sought to obliterate the mastoid cavity. This article demonstrates the extra dimension for the usage of fasciocutaneous flap from neck region to treat patients of recurrent postaural fistula.
\end{abstract}

Keywords: Postaural fistula, Fasciocutaneous flaps, Chronic otitis media- squamous type

\section{INTRODUCTION}

Post aural fistula is one of the complications of squamous variety of chronic otitis media (COM-S). For decades together a lot of new surgical techniques have been introduced in the treatment of COM-S out of which canal wall down mastoidectomy is most commonly practised. This includes lowering of the posterior canal wall and obliteration of the dependent portions of mastoid cavity primarily with bone dust, temporalis fascia or musculofascial flap etc. Despite these efforts many patients presenting with COM-S end up in tertiary referral centers at a late stage and by this time a number of procedures have already been done on them. These procedures further pose a greater challenge to the operating surgeon due to dearth of tissues available for reconstruction. The scalp tissues are already scarred and the temporalis fascia has already been used up. So newer flap options need to be sought to obliterate the cavity, which is the main reason for cavity problems like recurrent discharge. The other options for such situations are synthetic biointegrating material usage such as medpor etc. However an autologous tissue would always be a superior option in these cases. The neck skin like the facial skin has very good vascularity. Numerous randomly based flaps have been designed and executed for other reconstructions using such neck flaps in and around the neck region. This article demonstrates the usage of one such fasciocutaneous flap in the obliteration of mastoid cavity in a patient of recurrent postaural fistula as a complication of COM-S.

\section{CASE REPORT}

A 19 year old female presented with right sided postaural fistula with cavity problem of recurrent discharge. The patient was operated twice in the past. 
At the age of 5 years she had presented to a local practitioner for CSOM symptoms for which she was operated. The exact nature of surgery was unknown and she had recurrence of the symptoms shortly in the postop period. She was living with the same complaints for about 14 years. One year back, she was referred to higher centre for the persistent complaints of Postaural fistula as a complication of COM-S. The patient was evaluated and then optimized for surgery. Her preoperative findings revealed erosion of malleus, incus, suprastructure of stapes erosion by cholesteatoma. The scutum and posterosuperior canal wall were also found eroded.

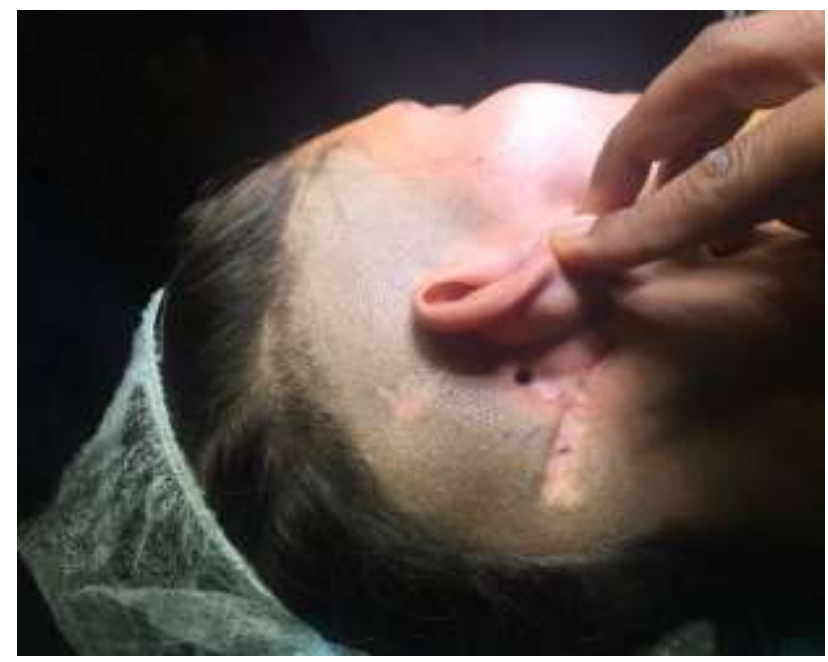

Figure 1: Preoperative view of the postaural fistula.

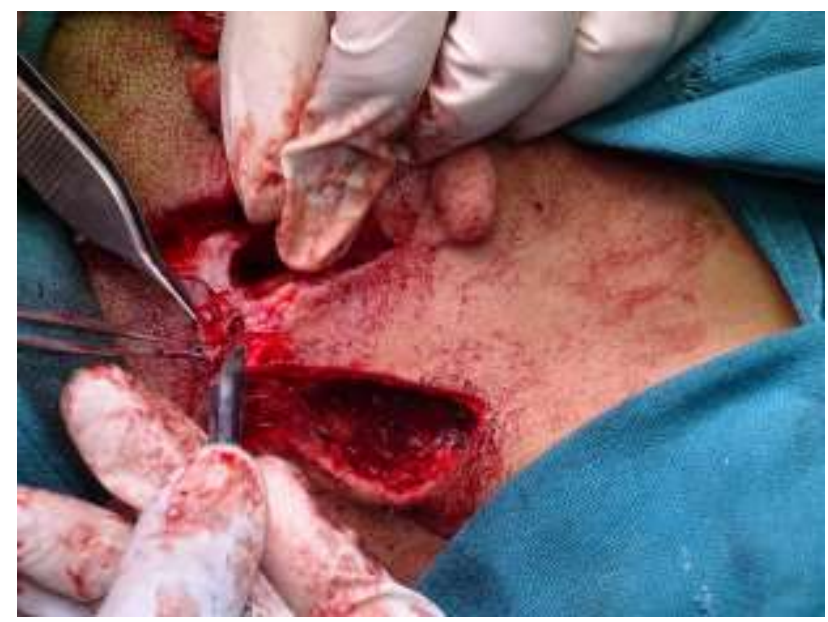

Figure 2: Fasciocutaneous flap deepithelialised.

She underwent modified radical mastoidectomy with type IV tympanoplasty with temporoparietal fascia graft over the foot plate of stapes. The postaural fistula andthe neighbouring scarred tissue were completely excised and a primary closure with the local scalp flaps was performed. But unfortunately despite these efforts the wound gaped on the fifth day and the problems of discharge and post aural fistula recurred.

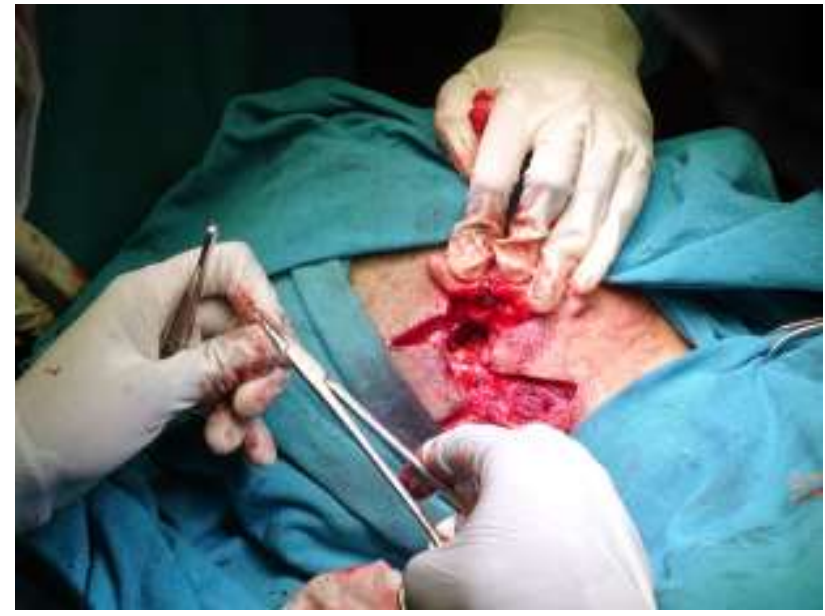

Figure 3: Fasciocutaneous flap secured.

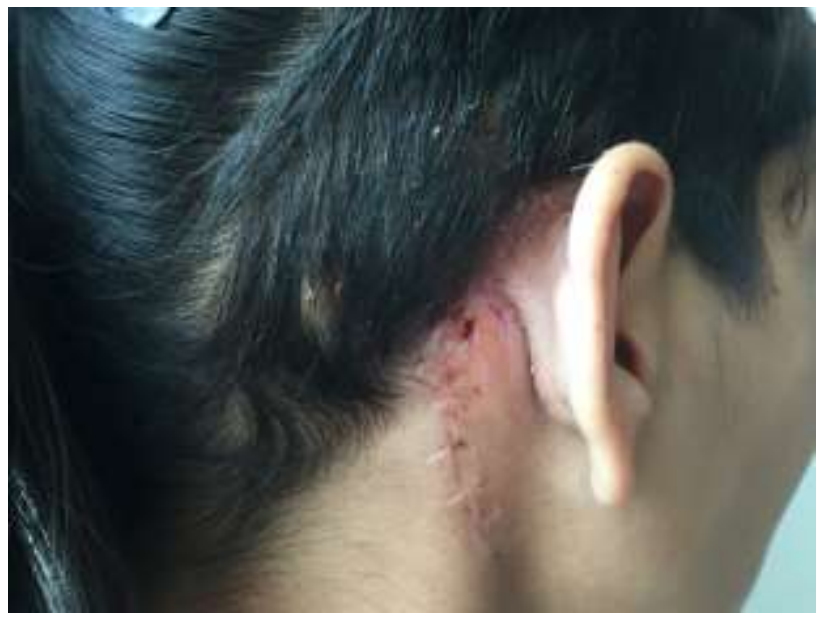

Figure 4: Postoperative follow up.

The patient was initially managed conservatively for these recurrent symptoms and observed for almost 1 year before she was prognosticated for a second revision surgery. However this time the disadvantages the surgeon had to face were the lack of bone pate due to the previous surgeries and unavailability of temporalis muscle and fascia flap due to the previous scarring and usage of temporalis fascia graft for the tympanoplasty procedure. Realizing this reconstructive plastic surgeon was introduced in the team and alternate strategies analyzed and surgical planning done. The fistula was re-explored, excised along with scarred tissues once again. A neck based random fasciocutaneous flap was planned just inferior to the flap. The flap was raised in the usual manner. The mastoid cavity explored. Debridement and burring of the cavity walls was done. Few pieces of conchal cartilages were harvested from the same ear with intact perichondrium and used to partially obliterate the cavity. The inferiorly based flap was then deepithelialised and the flap introduced in the cavity and was anchored to the cavity wall at the point of introduction of the flap by drilling through cavity wall using non absorbable sutures. The leading tip of the flap was also secured with the help of sutures secured through 
a hole drilled in the remnant of facial ridge. The purpose of the flap was to obliterate the mastoid cavity and to convert the dependent cavity into a shallow basin thus decreasing any stasis and hence infection and persistence of the disease.

The patient has recovered well and symptom free from that period.

It is hoped in the future that this flap may be helpful in such recurrent cases of COM-S where the usual options of temporalis fascia or muscle flap options have been utilized already or unavailable due to other problems. Also these flaps can be designed from the locally available tissues at the surgical site and are normally not tempered with in mastoid surgeries. They are highly vascular like the other flaps of the face and can support up to atleast 1:3 (width: length) dimensions. In older patients, this area is more lax due to skin and ligamental laxity and would be easier to elevate. This article also highlights the safe areas of the mastoid cavity which can be drilled in order to secure these types of flaps.

\section{DISCUSSION}

Traditionally mastoidectomies have been done by one of the two methods- canal wall down (CWD) and intact canal wall (ICW) procedures. The choice of procedure depends upon the acute nature of the disease and the persistence of the disease. These procedures have their own advantages and disadvantages. Though normal canal wall, middle ear anatomy and functions are maintained in ICW, leaving residual squamous epithelium during this surgery due to poor visibility may lead to recurrence and increased incidence of cholesteatoma.

CWD is a more difficult procedure that requires mastoid care for the patients' entire life. Also this procedure is not preferred before complete disease clearance. The use of a diamond burr at the end of the procedure over the cavity surface denudes the cavity of its vascularity and compromises epithelial regeneration. After a CWD procedure, the incidence of discharging mastoid cavity is around $10-66 \%{ }^{1}$

Post aural fistulas complicating a mastoidectomy surgery are very difficult to treat. The tracts are difficult to treat owing to the surrounding necrotic skin edges. The EAC would reveal keratinising squamous debris in the majority. $^{2}$

These fistulas are generally managed by excision of the tract and mastoid cavity obliteration. In addition, for complete mastoid cavity healing, disease clearance, adequate lowering of facial ridge, closure of Tympanic membrane and a very good meatoplasty are required. ${ }^{3}$

The cavity of mastoid can be obliterated using different synthetic and autologous materials. The synthetic materials like ceramic powder are scaffold forming materials that can integrate with the cavity and aid in the obliteration. The autologous tissues can vary from skin grafts, flaps to bone pate and cartilaginous grafts. ${ }^{4}$ The various autologous materials so far described for the obliteration are dermoadipose tissues, skin, muscle, fascial grafts, temporalis fascia with or without temporalis muscle autologous cultured epithelial cells and even free tissue transfers. ${ }^{5,3}$ Fascia lata grafts have also been used in solidarity or as augmenting tissues along with temporalis fascia. Some studies have also shown that the epicranial aponeurosis and scalp deep fascia which are vascular tissues are also good sources for cavity obliteration. ${ }^{5}$ Combination of medial conchal flap along with temporalis fascia flap ${ }^{6}$ has also been described.

Dermoadipose tissues often fail in the long term in cavity obliteration as they are crushed during harvest and at least $40 \%$ of these tissues are resorbed as they are free grafts. Musculoperiosteal and muscle flaps also shrink due to disuse atrophy but yet the resultant fibrous coating formed supports the growth of epithelium from the edges. Surface of mastoid cavity derives its vascularity from the bare bone surface and hence if the cavity is vascularised using tissues then it aids in the healing and this is the major reason for using autologous flap obliteration techniques in the management of such complex problems. The size of the discharging surface decreases drastically after cavity obliteration and epithelial regeneration of the remaining surface are hastened if vascularised graft is used. $^{7}$ Among the flaps, fasciocutaneous flaps are least described for the purpose of cavity obliteration. Some Surgeons have even used abdominal fat graft for the obliteration of these discharging cavities. ${ }^{8}$ In 2014,2 case reports of fasciocutaneous flaps from scalp were described. $^{9}$ The flaps were advancement flaps and because of their axis if they were to obliterate the whole mastoid cavity it would be difficult as it enters from a superolateral aspect relative to the cavity. The scalp area is normally scarred in these complicated cases of postaural fistula. Hence though new and interesting, the credibility of the flap is questioned. Since the flap is raised from hair bearing region, there is destruction of hair follicles and the consequent alopecia cannot be neglected.

In this article we are describing a similar fasciocutaneous flap, the major difference being that it is harvested from the neck, inferior to the fistula, which is a virgin territory. The axis of the flap is favourable. The flap can also be thicker depending upon the patients profile as compared to the scalp tissue which is normally thinner (the difference in subcutaneous tissue).

\section{CONCLUSION}

Postaural fistulas are dreaded complications of mastoidectomy surgery. Though numerous methods have been described in dealing with them vascularised flaps give the best results in mastoid cavity obliteration which 
is one of the major steps in their management. Fasciocutaneous flaps offer a simpler method by providing a vascularised tissue with relatively easy technique. The flaps described here have the added advantage of being harvested from non scarred region of neck and hence are more credible. In future they can be used as good workhorse flaps for such complications where the rest of the flap options have already been exhausted.

Funding: No funding sources Conflict of interest: None declared

Ethical approval: Not required

\section{REFERENCES}

1. Naik SM, Naik SS. Postoperative Mastoid Fistulas Managed by Fistulous Tract Excision and Cavity Obliteration by Epicranial Aponeurosis \& Temporalis Fibromuscular Flaps. Pakistan Journal of Otolaryngology. 2013;29:59-61.

2. Choo JC, Shaw Cl, Schong YC. Postauricular cutaneous mastoid fistula. J Laryngology and Otology. 2004; 118:893-94.

3. Wadhwa V, Anand TS, Kumar S. Periosteotemporofacial flap for cavity obliteration. Ind $\mathrm{J}$ Otolaryngol Head and Neck Surg 2003;55(3):170-4.
4. Thorburn IB. A clinical review of tympanoplastic surgery. J Laryngology and Otology. 1960;74:45374.

5. Gierek T, Klimczak-Golab L. Use of temporal fascia pedicle flap for the reconstruction of the posterior wall in the external auditory meatus and mastoid cavity obliteration of the process in the surgical treatment of cholesteatoma in COM. Otolary Pol. 1998;52(6):645-8.

6. Vira D, Andrews JC. Postauricular cutaneous mastoid fistula repair. Otolaryngol Head Neck Surg. 2012;147 (Suppl 2):218.

7. Gibb AG, Tan KK, Sim RST. The Singapore swing. Jou of Laryngology and Otology.1997;111:527-30.

8. Luetje CM. Postauricular mastoid cutaneous fistula: a method of closure. Otolaryngol Head Neck Surg. 1980; 88(1):90-2.

9. Olusesi AD, Opaluwah E. Postauricular advancement fascio-cutaneo periosteal flap for closure of mastoid cutaneous fistula. Otolaryngologia Polska. 2014;68(5):276-80.

Cite this article as: Vathulya M, Malhotra M, Varshney S. Extradimension of fasciocutaneous flap in the surgical management of postaural fistula, a complication of chronic otitis media - squamous type. Int J Otorhinolaryngol Head Neck Surg 2017;3:419-22. 